\title{
Modeling the Contribution of Gas Hydrate to Corrosion rate along the Subsea Pipelines
}

\author{
Obanijesu, E. O. , Pareek, V. and Tade, M. O. \\ Department of Chemical Engineering, Curtin University, Perth, WA 6102, Australia
}

\begin{abstract}
This study developed a corrosion predictive model along the deepwater gas pipelines with hydrate as the corroding agent. The model was developed and simulated with primary focus on the thermodynamic properties of each component of the gas mixture and a solution algorithm written with Matlab 6.5 code. The model was validated by comparing the generated results with the outputs of already established laboratory and mathematical corrosion studies; and the trends of the results obtained comparatively agreed with these studies to confirm its reliability. The model correctly predicted the relationships between corrosion rate and other thermodynamic parameters such as temperature, pressure, wall shear stress, velocity loss and $\mathrm{pH}$. This study showed that hydrates can initiate galvanic corrosion, stress cracking corrosion and erosion-corrosion amongst others. Furthermore, the resulting corrosion rate from the hydrates could be as high as $174 \mathrm{~mm} / \mathrm{year}(0.48 \mathrm{~mm} / \mathrm{day})$. This is extremely alarming compared to the industry's aim to operate below $2 \mathrm{~mm}$ /year. At this rate, an underwater pipeline would be subjected to full bore rupture within some days if corrective measures are not quickly taken; hence, the need for further studies.
\end{abstract}

Keywords: Gas hydrate; Corrosion rate; Modeling; Thermodynamic properties; Subsea pipelines.

* Correspondence Author

Email: e.obanijesu@curtin.edu.au; emmanuel257@yahoo.com

Tel: $\quad+61414512670$ 


\section{Introduction}

Natural gas transmission pipelines are generally constructed with carbon and low alloyed steels for economic, availability and strength purposes. They are however subject to the risk of internal corrosion attack as a result of the acidic gas(es) such as $\mathrm{CO}_{2}$ and/or $\mathrm{H}_{2} \mathrm{~S}$ that are present in the gas as contaminant(s). Internal corrosion was responsible for over $29 \%$ of global corrosion accidents between 1998 and 2008 (Mayberry, 2011) and about \$1.6 trillion dollars is annually spent on corrosion prevention and remediation. Apart from this enormous economic implication on the pipeline industry, the conveyed fluid usually escapes to the environment to pose the risk of fire, reduction in air quality and other health hazards to fauna and flora (Sonibare et al, 2010). Preventive measures are preferred over the corrective measures in minimizing the corrosion initiation and promotional rate, and the development of mathematical models as the preventive measure is more favored by the industry. This helps to predict the likely shelf-life of the pipes; thus, assisting in avoiding the eventual ruptures and the associated financial implications assisting in planning for their replacement time.

Internal corrosion of pipeline is mostly localized and several predictive models have been developed on localized corrosion rate. A probabilistic model was developed by Melchers (2003) which divided the corrosion process into four stages while Schwermer et al (2008) showed that patchy bacterial colonies could enhance corrosion by formation of differential aeration cells while Obanijesu (2009) applied Norsok Standard (2005) to predict the contribution of $\mathrm{H}_{2} \mathrm{~S}$ to offshore pipeline corrosion. However, none of the available predictive model has ever considered the ability of hydrates to initiate corrosion along the gas pipeline; hence, the significance of this model.

This article used the thermodynamic properties of an industrially prepared natural gas to develop an empirical model for predicting the contribution of gas hydrate to corrosion rate during offshore transmission operations. The model accounted for all the gas components and, considered a carbon steel pipeline having iron as the alloyed metal and operating at turbulent flow, closed system and homogenous phase conditions. Availability and perfection of this model would be a great asset for pipeline industry during the design stage to develop the necessary management plans for its operation at subsea regions. 


\section{Model Development}

This model was developed based on the industrially prepared natural gas composition used by Obanijesu (2012) for laboratory studies. It was established from the studies that the gas composition formed hydrates at $10^{\circ} \mathrm{C}-18^{\circ} \mathrm{C}$ range for 50 bar -150 bar pressure range. The gas contains $20 \% \mathrm{CO}_{2}$ and the hydrate composition was calculated based on $90 \%$ water and $10 \%$ gas components as recommended by Abdel-Aal et al (2003). Norsork Standard (2005) gave the corrosion rate equation for operating temperature range of $5^{\circ} \mathrm{C} \leq \mathrm{T} \leq 15^{\circ} \mathrm{C}$ as

$C_{r t=} K_{T} * f_{T}^{0.36} *\left(\frac{S}{19}\right)^{0.146+0.0324\left(\log f_{T}\right)} * f(p H)_{T}$

Where

$K_{T}$ is a constant; $f_{T}$ is the Friction faction; $\left(f(p H)_{T}\right)$ is the $\mathrm{pH}$ factor and $S$ is the Wall shear stress.

The $\mathrm{pH}$ factor $\left(f(p H)_{T}\right)$ within this operating temperature range is given as

$f(p H)_{T}=2.0676-(0.2309 * p H)$

$3.5 \leq \mathrm{pH} \leq 4.6$

Or

$f(p H)_{T}=4.986-(01.191 * p H) *\left(0.0708 * p H^{2}\right)$

$4.6 \leq \mathrm{pH} \leq 6.5$

Obanijesu (2009) gave the values of $K_{T}$ different temperatures.

\section{Calculating the Wall Shear Stress (S)}

Wall shear stress is an important parameter in determining corrosion rate since high shear stress may cause mesa corrosion attach (Singh and Krishnathasan, 2009). Wall shear stress is a function of friction factor at the specific temperature $\left(f_{T}\right)$, mixture density $\left(\rho_{m}\right)$ and superficial velocity $\left(U_{m}\right)$. It is given by Norsork Standard (2005) as

$S=0.5 * \rho_{m} * f_{T} * U_{m}$

Where the friction factor $\left(f_{T}\right)$ is given as

$f_{T}=0.001375\left[1+\left(20000 \frac{k}{D}+10^{6} \frac{\mu_{m}}{\rho_{m} U_{m} D}\right)^{0.33}\right]$ 
The mixture density $\left(\rho_{m}\right)$, mixture velocity $\left(U_{m}\right)$ and mixture viscosity $\left(\mu_{m}\right)$ are respectively calculated as equations (6-8) while the liquid fraction is given as equation 9.

$$
\begin{aligned}
& \rho_{m}=\sum \rho_{m_{i}}=\sum\left(\rho_{L} \lambda+\rho_{G}(1-\lambda)\right) \\
& U_{m}=\sum U_{m_{i}}=\sum\left(U_{L}^{S}+U_{G}^{S}\right) \\
& \mu_{m}=\sum \mu_{m_{i}}=\sum\left(\mu_{L} \lambda+\mu_{G}(1-\lambda)\right) \\
& \lambda=\frac{Q_{L}}{Q_{L}+Q_{G}}
\end{aligned}
$$

\section{The formation fugacity $(f)$}

Every molecule in hydrate is gaseous except for water molecule. For this condition and high operating pressure, the partial pressure of individual gas should be multiplied by its fugacity constant as shown in Equation 10, since an ideal gas situation could no longer be assumed.

$f=\sum f_{i}=\sum\left(a * P_{i}\right)$

Where $a$ is the fugacity coefficient and $P_{i}$ is the partial pressure of component $\mathrm{i}$. The partial pressure $P_{i}$ is found using

$P_{i}=\frac{\text { Mass flow of component } i \text { in the gas stream }\left(\mathrm{kmoleh}^{-1}\right) * \text { Total pressure }}{\text { Total mass flow in the gas phase }\left(\mathrm{kmoleh}^{-1}\right)}$

The fugacity coefficient $(a)$ as a function of temperature and pressure is given by Waard et al (1991) as

$$
\begin{array}{lr}
a=10^{P *\left(0.0031-\frac{1.4}{T}\right)} & P \leq 250 \mathrm{bar} \\
a=10^{2.5 *\left(0.0031-\frac{1.4}{T}\right)} & P>250 \mathrm{bar}
\end{array}
$$

Since $a$ is a constant for the system, then,

$f=\sum f_{i}=a * \sum\left(P_{i}\right)$

\section{Model Simulation}

The hydrate composition for this work was computed as

$$
X_{G H C}=\frac{\text { Total Hydrate-Water content }}{\text { Total Hydrate }} * X_{N G C}
$$


Where

$X_{G H C}=$ Mole fraction of gas $\mathrm{X}$ in the hydrate; $X_{N G C}=$ Mole fraction of gas $\mathrm{X}$ in the natural gas stream; Water content $=90 \%$

\section{Calculation of the Fluid Fugacity}

The fugacity of a fluid is given by Smith et al (2004) as

$\ln \frac{f}{P}=\frac{\Delta G}{R T}$

Therefore, upon re-arrangement, the fugacity for a multi-component stream becomes

$f=\sum\left(P_{i} * e^{\left(\frac{\Delta G_{i}}{R T}\right)}\right)$

A component's Gibb-free energy $\left(\Delta G_{i}\right)$ is a state property which is expressed as

$\Delta G_{i}=\Delta H_{i}-T \Delta S_{i}$

Each component's enthalpy change $\left(\Delta H_{i}\right)$ and entropy change $\left(\Delta S_{i}\right)$ are respectively given as

$\Delta H_{i}=\int_{T_{o}}^{T} C_{p_{i}} d T$

$\frac{\Delta S_{i}}{R}=\int_{T_{o}}^{T} \frac{C_{p_{i}}}{R} d T-\ln \frac{P_{i}}{P_{o}}$

Equations $18-20$ are property related only and are completely independent of the process causing the change of state. $C_{p_{i}}$ is temperature dependent however and expressed as

$\frac{C_{p_{i}}}{R}=A_{i}+B_{i} T+C_{i} T^{2}+D_{i} T^{-2}$

Thermodynamically, the temperature dependence of Equation 21 allows for the integration of Equation 19 and Equation 20 to give more simplified equations for the enthalpy change and entropy change respectively as

$\frac{\Delta H_{i}}{R}=A_{i} T_{o}(\tau-1)+\frac{B_{i}}{2} T_{o}{ }^{2}\left(\tau^{2}-1\right)+\frac{C_{i}}{3} T_{o}{ }^{3}\left(\tau^{3}-1\right)+\frac{D_{i}}{T_{o}}\left(\frac{\tau-1}{\tau}\right)$

$\frac{\Delta S_{i}}{R}=A_{i} \ln \tau+\left[B_{i} T_{o}+\left(C_{i} T_{o}{ }^{2}+\frac{D_{i}}{\tau^{2 T_{o}{ }^{2}}}\right)\left(\frac{\tau+1}{2}\right)\right](\tau-1)-\ln \frac{P_{i}}{P_{o}}$

Where

$\tau=\frac{T}{T_{o}}$ 
$\frac{C_{p_{i}}}{R}$ is dimensionless, thus, the unit of $C_{p}$ depends mainly on that of $R$ chosen. A, B, C and D are constant for each fluid regardless of the operating conditions with either $\mathrm{C}$ or $\mathrm{D}$ equal to zero. The values for gases used in this study are available in Smith et al (2004).

\section{Calculation of the wall shear stress}

The gas density $\left(\rho_{G}\right)$ and liquid density $\left(\rho_{L}\right)$ in Equation 6 are given by NS (2005) as

$\rho_{G}=\frac{627.1047 * P * \rho_{g}}{Z *\left(460+T_{f}\right)}$

$\rho_{L}=\emptyset \rho_{w}+\rho_{G}(1-\lambda)$

Water is the only liquid in the hydrate for this study; therefore, $\rho_{L}$ is not a multi-component parameter but $\rho_{G}$ is a multi-component parameter (Table 1). It is estimated as for each gas as

$\rho_{G}=\sum \rho_{G_{i}}=\sum \frac{627.1047 * P_{i} * \rho_{g_{i}}}{Z_{i} *\left(460+T_{f}\right)}$

Furthermore, the compressibility factor for each component $\left(Z_{i}\right)$, was calculated using the

Ptizer Correlations for the Second Virial Coefficient given as

$Z_{i}=Z_{i}^{o}+w_{i} Z_{i}^{\prime}$

Where

$Z_{i}^{o}$ and $Z_{i}^{\prime}=f\left(T_{r_{i}}, P_{r_{i}}\right)$

$T_{r_{i}}=\frac{T}{T_{c_{i}}} ; \quad$ and $\quad P_{r_{i}}=\frac{P}{P_{c_{i}}}$

Thermodynamically, $Z_{i}{ }^{o}$ and $Z_{i}{ }^{\prime}$ are respectively represented as

$Z_{i}^{o}=1+B_{i}^{o} \frac{P_{r_{i}}}{T_{r_{i}}}$

$Z_{i}^{\prime}=B_{i}{ }^{\prime} \frac{P_{r_{i}}}{T_{r_{i}}}$

Where $B_{i}{ }^{o}$ and $B_{i}{ }^{\prime}$ are given by

$B_{i}{ }^{o}=0.083-\frac{0.422}{T_{r_{i}}{ }^{1.6}} \quad$ and $\quad B_{i}{ }^{\prime}=0.139-\frac{0.172}{T_{r_{i}}{ }^{4.2}}$

Substituting Equations 31, 32 and 33 into Equation 28 gives 
$Z_{i}=1+\left(0.083-\frac{0.422}{T_{r_{i}}{ }^{1.6}}\right) \frac{P_{r_{i}}}{T_{r_{i}}}+w_{i}\left(0.139-\frac{0.172}{T_{r_{i}}{ }^{4.2}}\right) \frac{P_{r_{i}}}{T_{r_{i}}}$

Therefore, for a multi-component system,

$Z=\sum Z_{i}=\sum\left\{1+\left(0.083-\frac{0.422}{T_{r_{i}}{ }^{1.6}}\right) \frac{P_{r_{i}}}{T_{r_{i}}}+w_{i}\left(0.139-\frac{0.172}{T_{r_{i}}^{4.2}}\right) \frac{P_{r_{i}}}{T_{r_{i}}}\right\}$

Corresponding values for $w_{i}, T_{c_{i}}$ and $P_{c_{i}}$ are available in Smith et al (2004).

The associated water in the hydrate is considered to be incompressible while the gases are compressible. Therefore, the liquid superficial velocity $\left(U_{L}{ }^{s}\right)$ and the gas superficial velocity $\left(U_{G}{ }^{s}\right)$ are respectively given as

$U_{L}^{s}=\frac{Q_{L}}{A}$

$U_{G}^{s}=\left(\frac{Q_{G}}{A}\right) Z\left(\frac{T}{T_{s t d}}\right)$

The water viscosity $\left(\mu_{w}\right)$ as a function of temperature only at different operating conditions is expressed by Lide (2006) as

$\mu_{w}=10^{\left(\frac{1301}{\left(998.333+8.1855(T-20)+0.00585(T-20)^{2}\right)}\right)-1.30233} * 10^{-3} \quad 0^{\circ} \mathrm{C} \leq T \leq 20^{\circ} \mathrm{C}$

and

$\mu_{w}=1.002 *\left(10^{\left(\frac{1.3272(T-20)-0.001053(T-20)^{2}}{(T+105)}\right)} * 10^{-3}\right) \quad 20^{\circ} \mathrm{C} \leq T \leq 100^{\circ} \mathrm{C}$

For this study, the liquid viscosity $\left(\mu_{L}\right)$ is assumed to be equal to $\mu_{w}$ since water is the main liquid in the hydrate while other component(s) that might liquefy within these temperature ranges and high pressure are infinitesimal. Therefore,

$\mu_{L}=\mu_{w}$

The gas viscosity $\left(\mu_{G}\right)$ for the hydrate fluid was calculated using the Sutherland's viscosity law with 3-co-efficient expressed by Roux et al (2008) as

$\mu_{G}=\mu_{o}\left[\left(\frac{T}{T_{o}}\right)^{\frac{3}{2}} \frac{T_{o}+S}{T+S}\right]$

Where $\mu_{G}=$ gas viscosity in $\mathrm{Kg} / \mathrm{m}-s ; \mu_{o}=$ a reference viscosity in $\mathrm{Kg} / \mathrm{m}-s ; T_{o}=$ a reference Temperature $(K) ; T=$ the static Temperature $(K) ; S=$ an Effective Temperature also known as Sunderland constant which is the characteristic of the gas $(K)$. 
Sutherland gave the viscosity law in 1893 from a kinetic theory by using an idealized intermolecular-force potential with the reference points in the Equation (41) given in Table 1. A flowchart was developed and a computer code written in MATLAB to solve the equations.

\section{Results and Discussions}

The trend of the results obtained from the model agreed comparatively with various existing similar models and experimental studies. The effect of temperature and wall shear stress on corrosion rate as predicted by the model at $100 \mathrm{bar}$ and $\mathrm{pH}$ of 5.0 is presented as Figure 1a. The Figure showed that the corrosion rate increases with temperature; this perfectly agreed with various existing related experimental and predictive models (Xiang et al, 2013). This could be attributed to the temperature's secondary effects through its influence on the solubility of the available corroding agents in the hydrate. This includes the ability of $\mathrm{CO}_{2}$ to be more soluble in $\mathrm{H}_{2} \mathrm{O}$ to produce more of $\mathrm{H}_{2} \mathrm{CO}_{3}$. According to the reaction kinetic shown through Equations 42 and 43, the weak acid $\left(\mathrm{H}_{2} \mathrm{CO}_{3}\right)$ easily dissociates to produce more of hydrogen radicals $\left(H^{*}\right)$ that is required for electrochemical reaction(s).

$\mathrm{CO}_{2}+\mathrm{H}_{2} \mathrm{O} \rightleftharpoons \mathrm{H}_{2} \mathrm{CO}_{3}$

$\mathrm{H}_{2} \mathrm{CO}_{3} \rightleftharpoons \mathrm{H}^{*}+\mathrm{HCO}_{3}^{*}$

Due to availability of this radical, the internal surface of the pipeline becomes anodic and cathodic spots based on the use of two or more metallic alloyed of different cell potentials $\left(\mathrm{E}^{0}\right)$ as material of construction for the pipeline. Corrosion reactions are then promoted over time from these radicals through electron transfers (Equation 44 and 45) to yield galvanic and electrolytic corrosions (Figures $2 \mathrm{a} \& \mathrm{~b}$ ). Each of these corrosion types is capable of singlehandedly collapsing a pipeline; also, they can individually or collectively initiate pitting corrosion or Stress cracking corrosion (SCC).

Anode: $\quad \mathrm{Fe} \rightarrow \mathrm{Fe}^{2+}+2 e^{-}$

Cathode: $\quad 2 H^{+}+2 e^{-} \rightarrow H_{2}$

Figure 1a also agreed with related studies to show that corrosion rate increases with wall shear stress (Ige et al, 2013). According to Mochizuki (2007), corrosion can be accelerated through either residual internal stress in the pipe or externally applied stress. Residual stresses are usually produced by deformation during the pipeline fabrication, unequal cooling from 
high temperature and/or the internal structure arrangements that involve the volume change. The geometrical changes and any obstacles in the flow regime also give rise to higher shear stress. Again, the different flow regimes and geometrical obstacles may generate flunctuation in shear stress at those points where the shear stress peaks may be considerably higher than the average shear stress.

The unequal cooling or heating along resulting from the continuous change in temperature profile along the pipe-length during subsea gas transport could cause a cubic expansion within the pipe's material (Ye et al, 2013). This expansion ultimately leads to unequal internal structure arrangement to cause a SCC (Figure 2c).

Alternatively, the residual internal stress could be produced by the operating temperature. Temperature is always kept high during the operation to prevent hydrate formation and/or the liquefaction of some other components during operation. Since the steel pipeline is composed of many crystals of about $0.05 \mathrm{~mm}$ (Itakura et al, 2005), this high temperature may generate irradiation inside the steel and subject the material to tensile stress in a corrosive environment, thus, causing the SCC.

When SCC occurs, its intricate crack shape follows the interface between these grains in a zigzag manner. There can be multiple cracks in the pipeline, thus, making the study of SCC progression in a pipe-length very crucial for the pipe's safety assessment.

Specifically, Figure 1a showed that within the studied hydrate formation temperature range and 100bar, the corrosion rate for the transportation pipeline is about $175 \mathrm{~mm} / \mathrm{yr}$ $(0.48 \mathrm{~mm} /$ day $)$. This is alarming since at this rate, the transmission pipeline may be subject to permanent failure within days or weeks. This is true since hydrate chips will be increasing in size to create more stress through geometrical changes and obstacles creation.

Furthermore, Figure 1b showed that increase in operating pressure leads to increase in corrosion rate as well as increase in velocity loss. From the thermodynamic properties of hydrate formation, this pressure-corrosion relationship obtained is correct since increase in pressure produces more hydrate (Sarshar et al, 2010). The resulting high velocity flow of fluid inside the pipe due to increasing operating pressure coupled with the increasing hydrate chips will ultimately lead to cavitation corrosion or erosion corrosion based on the state of the hydrate chips.

Since the hydrate's first formation stage is a semi-solid state, this will readily collapse at high impact with the pipe's rigid surface to cause the collapse of bubbles formed at areas of low 
pressure in the conveyed fluid. This will produce a shock wave sufficiently strong enough to remove the protective films and initiate the cavitations corrosion. Alternatively, erosioncorrosion would result in case the hydrate has reached the total solid state before the constant bombardment of the particles on the pipe's inner surface. The solidified hydrate chips would gradually remove the protective film or the metal oxide from the metal surface and expose it to erosion-corrosion from the corroding agents available in the fluid.

Again, an increase in the operating pressure would lead to increase in velocity along the pipelength; this would increase agitation in the transport fluid which aids hydrate formation through turbulence (Wenji et al, 2009). At choke also, temperature drop will be experienced through Joule Thompson effects to further promote the formation (Harun and Watt, 2009) while the presence of welded spots (elbows, tee, etc), dirt, scales, slits and sands along the pipe will make good nucleation sites and the available free-water will be an enhancer due to gas-water interface. With time, the hydrates formed will increase in quantity and size through agglomeration inside the pipeline. This will cause reduction in the pipe's orifice, thus, resulting into velocity loss. This ultimately results into line plugging, pressure build-up and eventual pipeline rupture.

Again, the model was used to predict the impact of $\mathrm{pH}$ on corrosion rate along the longitudinal section of a pipeline (Figure 1c). This impact depends on the soluble corroding agent and the types of metallic alloys used for the pipe's construction. If the metals are acid soluble, the corrosion rate would be controlled by the rate of transport of available oxidizer to the metal surface. Amphoteric metals such as aluminum and zinc dissolve rapidly in acidic or basic solutions to aid corrosion while noble metals such as gold and platinum are not appreciably affected by $\mathrm{pH}$.

Figure 1c obtained from the model agreed with NPF (2013) that $\mathrm{pH}$ hardly influences corrosion rate of iron within the $\mathrm{pH}$ region of 4 - 10. Within this range, corrosion rate of iron is relatively independent of $\mathrm{pH}$ for it is governed mostly by the rate at which oxygen would react with the absorbed atomic hydrogen. This will depolarize the pipe's surface and allow continuation of the reduction reaction.

Ferrous oxide $(\mathrm{FeO})$ is however soluble below $\mathrm{pH}$ of 4 and would dissolve upon formation rather than being deposited on the metal surface for film formation. The pipe's surface will directly be in contact with the acid solution due to an absence of the protective film, and this will result in sharp increase in corrosion rate. At this lower $\mathrm{pH}$ range, corrosion rate is 
dependent on both the depolarization of oxygen and hydrogen evolution since hydrogen will be produced in the acid solution at this lower $\mathrm{pH}$ range. Above $\mathrm{pH}$ of 10, corrosion rate decreases with an increase in $\mathrm{pH}$ probably due to the increase in reaction rate of oxygen with hydrated $\mathrm{FeO}\left(\mathrm{Fe}(\mathrm{OH})_{2}\right)$ to form a more protective $\mathrm{FeO}$ in the oxide layer.

The sharp variation noticed at $\mathrm{pH}$ of 4.6 in Figure $1 \mathrm{c}$ is due to the change in the condition of influence corrosion modeling formula at this point as indicated by Equations 2 and 3. This further confirmed the appropriateness of the developed MATLAB code used for simulation.

\section{Conclusions}

The model adequately predicted the pipe's shelf-life due to corrosion initiated through hydrate formed within a pipeline transporting natural gas at deepwater location and its effectiveness is confirmed by the ability of its plotted trends which comparatively agreed with existing literatures. The resulting corrosion rates from this model increased with temperature, pressure and wall shear stress. These agreed with the existing mathematical and experimental reports, hence, the reliability of this predictive model. This model predicted that the resulting corrosion rate from hydrates alone could be as high as $174 \mathrm{~mm} / \mathrm{yr}(0.48 \mathrm{~mm} /$ day $)$ as against the proposed industrial desire of less than $2 \mathrm{~mm} / \mathrm{yr}$. This predicted rate is extremely alarming and would subject a pipeline would to full bore rupture within some days if corrective actions are not quickly taken. This will further negatively impact operation by reducing the pipe-shelf life as well as the pipe's integrity. This model further agreed with existing literature that an increase in operating pressure increases the hydrate formation temperature. This increase in operating pressure also promotes the initiation of erosioncorrosion as well as increases the rate of velocity loss along the pipeline. Furthermore, this increase in temperature will have secondary effects through its influence on the solubility of the corroding agent(s). Since $\mathrm{CO}_{2}$ as the corroding agent for this study is very soluble in the formation water, any change in temperature would have resulting effects on other factors influencing the corrosion rate.

Finally, this model is a point corrosion rate model since the parameters needed are subject to various operating conditions which could often change with distance within the pipe-length. 


\section{REFERENCES}

Abdel-Aal, H.K., Aggour, M. and Fahim, M.A. (2003), "Petroleum and Gas Field Prosessing”, Marcel Dekker Inc., New York, USA.

FLUENT Incorporated (2005), "Viscosity as a Function of Temperature", Accessed from http://sydney.edu.au/engineering/aeromech/AMME4210/old_manuals/manuals/fluent_help/htm 1/ug/node300.htm on $12^{\text {th }}$ December, 2011.

Harun, A.F., and Watt, N. (2009), "Bringing the 1st BP Operated Subsea to Shore Gas Field into Production: Flow Assurance Lessons Learned", Asia Pacific Oil and Gas Conference \& Exhibition, Society of Petroleum Engineers, Jakarta, Indonesia, 4-6 August.

Ige, O.O., Barker, R., Hu, X., Umoru, L.E. and Neville, A. (2013), “Assessing the Influence of Shear Stress and Particle Impingement on Inhibitor Efficiency through the Application of Insitu Electrochemistry in a $\mathrm{CO}_{2}$-Saturated Environment", Wear, Vol. 304, Iss. 1-2, pp. 49-59

Lide, D.R (2006), "CRC Handbook of Chemistry and Physics" $87^{\text {th }}$ Edition, CRC Press Inc, Boca Raton, Fl, U.S.A.

Mayberry, A.K. (2011), “Internal Corrosion Consideration”, Office of Pipeline Safety, Pipeline and Hazardous Materials Safety Administration, US Department of Transport, pp. 1-17

Melchers, R. (2003), "Modeling of Marine Immersion Corrosion for Mild and Low alloy Steels - Part 1 Phenomenological Model”, CORROSION, Vol. 59, Iss 4, pp. 319-334

Mochizuki, M. (2007), “Control of Welding Residual Stress for Ensuring Integrity against Fatigue and Stress-Corrosion Cracking”, Nuclear Engineering and Design, Vol. 237, Iss. 2, pp. $107-123$

NORSORK STANDARD (2005), "CO $\mathrm{CO}_{2}$ Corrosion Rate Calculation Model", Norwegian Technological Standards Institute, Oscarsgt. 20, Majorstural, NORWAY.

NPF (2013), "Effect of pH on the Corrosion Rate of Iron in Water", Integrated Publishing. Retrieved on 17 June 2013 at http://www.tpub.com/content/doe/h1015v1/css/h1015v1_117.htm

Obanijesu, E.O. (2009), "Modeling the $\mathrm{H}_{2} \mathrm{~S}$ Contribution in Corrosion Rate of Natural Gas Pipeline", Energy Sources Part A: Recovery, Utilization and Environmental Effects, Vol. 31, Iss. 4, pp 348-363

Obanijesu, E.O. (2012), “Corrosion and Hydrate Formation in Natural Gas Pipelines”, Ph.D. Thesis, Curtin University, Perth, Australia. 
Roux, A., Gicquel, L.Y.M, Sommerer, Y. and Poinsot, T.J. (2008), "Large Eddy Simulation of Mean and Oscillating Flow in a Side-Dump Ramjet Combustor", Combustion and Flame, Vol. 152, Iss. 1-2, pp. 154-176.

Sarshar, M., Fathikalajahi, J. and Esmaeilzadeh, F. (2010), "Experimental and Theoretical Study of Gas Hydrate Formation in a High-Pressure Flow Loop", The Canadian Journal of Chemical Engineering, Vol. 88, Iss. 5, pp. 751-757

Schwermer, C.U., Lavik, G., Abed, R.M.M., Dunsmore, B., Ferdelman, T.G., Stoodley, P., Gieseke, A. and Dirk de Beer, D. (2008), "Impact of Nitrate on the Structure and Function of Bacterial Biofilm Communities in Pipelines Used for Injection of Seawater into Oil Fields, Applied and Environmental Microbiology, Vol. 74, No. 9, pp. 2841-2851

Singh, B. and Krishnathasan, K. (2009), "Pragmatic Effects of Flow on Corrosion Prediction", Corrosion 2009 Conference \& Expo, NACE International, Atlanta, GA, March 22 - 26, Paper No. 09275, pp. 1-29

Smith, J.M., Van Ness, H.C. and Abbott, M.M. (2004), "Introduction to Chemical Engineering Thermodynamics", $7^{\text {th }}$ Edition, McGraw-Hills, New York.

Sonibare, J.A, Adebiyi, F.M, Obanijesu, E.O and Okelana, O.A. (2010), “Air Quality Index Pattern around Petroleum Production Facilities", Management of Environmental Quality: An Internal Journal, Vol. 21, Iss. 3, pp. 379-392.

TET (2013), “Gases-Densities: Densities and molecular weights of some common gases acetylene, air, methane, nitrogen, oxygen and many others", The Engineering Toolbox. Accessed on 3 March 2013 at http://www.engineeringtoolbox.com/gas-density-d_158.html

Wenji, S., Rui, X., Chong, H., Shihui, H., Kaijun, D.,and Ziping, F. (2009), "Experimental investigation on TBAB Clathrate Hydrate Slurry Flows in a Horizontal Tube: Forced Convective Heat Transfer Behaviors", International Journal of Refrigeration, Vol. 32, Iss. 7, pp. 1801-1807.

Xiang, Y., Wang, Z., Li Z. and Ni, W. D. (2013), "Effect of Temperature on Corrosion Behaviour of X70 Steel in High Pressure $\mathrm{CO}_{2} / \mathrm{SO}_{2} / \mathrm{O}_{2} / \mathrm{H}_{2} \mathrm{O}$ Environments", Corrosion Engineering, Science and Technology, Vol 48, NO 2, pp. 121-129

Ye, X., Zhang, K. and Zuo, J. (2013), "The Research of Controlled Rolling and Cooling Process in X70 Grade Pipeline Steel with Vanadium Microalloying”, Advanced Materials Research, Vol. 393 - 395, pp. 1033-1037 
Table 1: The raw values for some applied parameters

Mol. wt, $\rho$ and $\rho_{g}$ for the hydrate components (TET, 2013)

\begin{tabular}{|c|c|c|c|c|}
\hline Component & $\begin{array}{c}\text { Molecular wt } \\
(\mathrm{Kg} / \mathrm{Kmol})\end{array}$ & $\begin{array}{l}\rho(\mathrm{NTP}) \\
\left(\mathrm{Kg} / \mathrm{m}^{3}\right)\end{array}$ & $\begin{array}{l}\rho(\mathrm{STP}) \\
\left(\mathrm{Kg} / \mathrm{m}^{3}\right)\end{array}$ & $\rho_{g}$ \\
\hline $\mathrm{CH}_{4}$ & 16.043 & 0.668 & 0.717 & 0.5537 \\
\hline $\mathrm{C}_{2} \mathrm{H}_{6}$ & 30.07 & 1.264 & & 1.0378 \\
\hline $\mathrm{C}_{3} \mathrm{H}_{8}$ & 44.09 & 1.882 & & 1.5219 \\
\hline $\mathrm{n}-\mathrm{C}_{4} \mathrm{H}_{10}$ & 58.1 & 2.489 & 2.500 & 2.0061 \\
\hline $\mathrm{n}-\mathrm{C}_{5} \mathrm{H}_{12}$ & & & & 2.487 \\
\hline $\mathrm{N}_{2}$ & 28.02 & 1.165 & 1.2506 & 0.9669 \\
\hline $\mathrm{CO}_{2}$ & 44.01 & 1.842 & 1.977 & 1.5189 \\
\hline $\mathrm{H}_{2} \mathrm{O}_{(\mathrm{l})}$ & 18.016 & 0.804 & 0.804 & \\
\hline \multicolumn{5}{|c|}{ Values for Sutherland's reference points (FLUENTS Incorporated, 2001) } \\
\hline \multicolumn{2}{|c|}{ Parameter } & \multicolumn{3}{|c|}{ Value } \\
\hline \multicolumn{2}{|c|}{$\mu_{o}$} & \multicolumn{3}{|c|}{$1.7894 * 10^{-5}$} \\
\hline \multicolumn{2}{|c|}{$T_{o}$} & \multicolumn{3}{|c|}{273.11} \\
\hline \multicolumn{2}{|c|}{$S$} & \multicolumn{3}{|c|}{110.56} \\
\hline
\end{tabular}




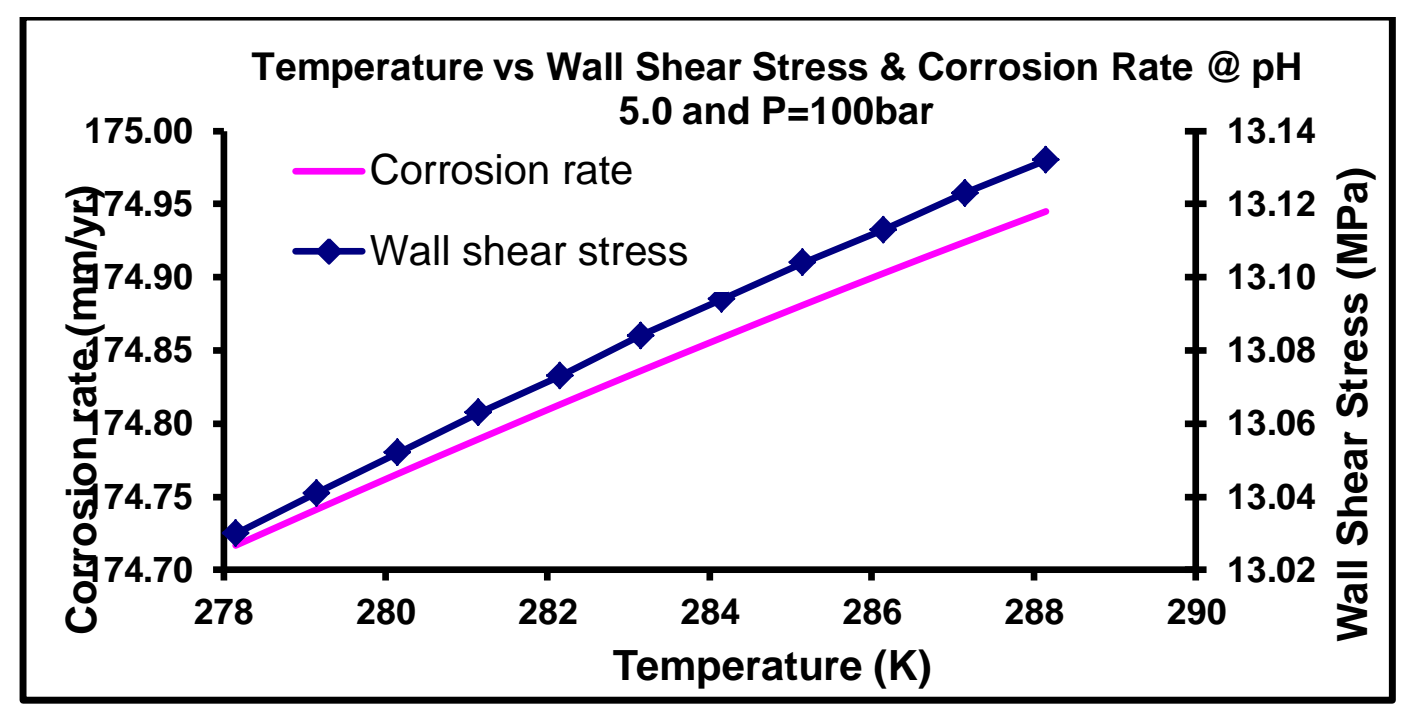

Figure 1a: Temperature against wall shear stress and corrosion rate at $\mathrm{pH}=5.0$ and 100bar

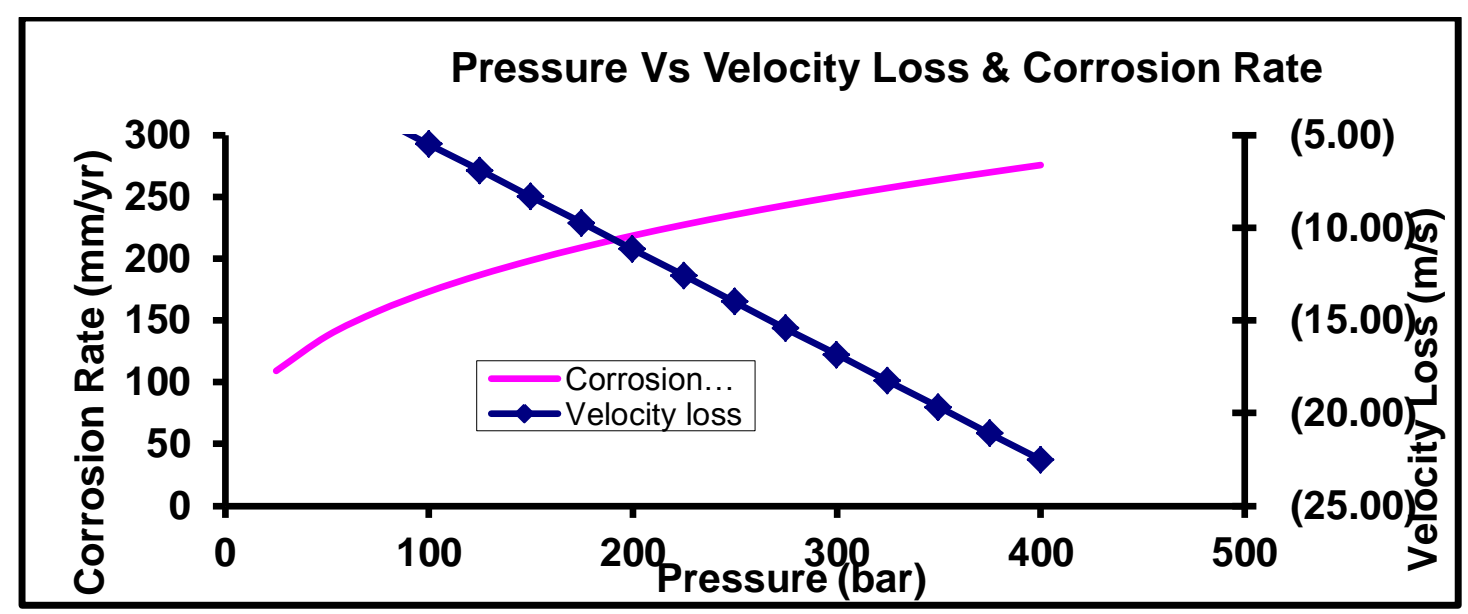

Figure 1b: Pressure against velocity loss and corrosion rate at $15^{\circ} \mathrm{C}$ and $\mathrm{pH}=5.0$

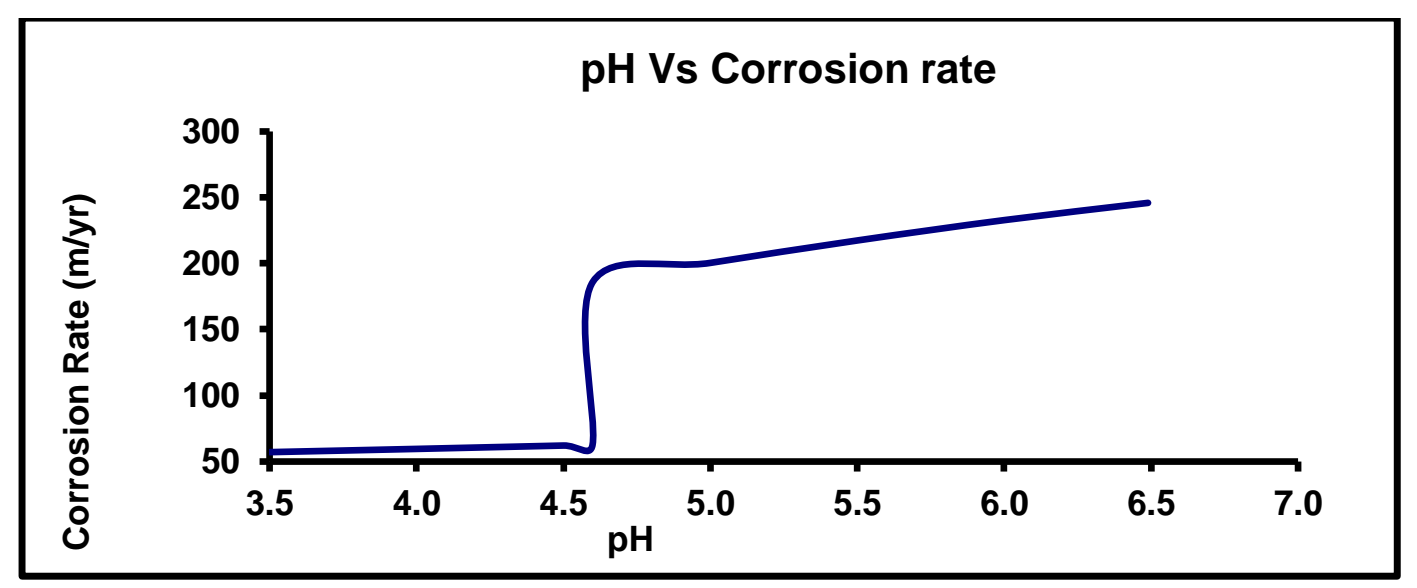

Figure 1c: Impact of $\mathrm{pH}$ on corrosion rate. 




(a): Galvanic attack

Obanijesu (2012)
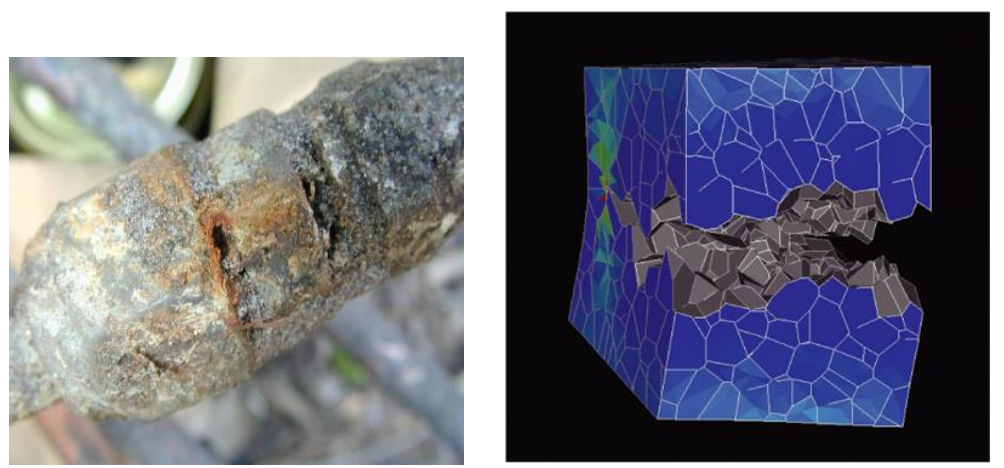

(b): Electrolytic attack

Obanijesu (2012) (c): 3-D SCC attack

Itakura et al (2005)

Figure 2: Some of the possible corrosion attacks. 